\title{
Dielectric and piezoelectric properties of neodymium oxide doped lead zirconate titanate ceramics
}

\author{
JANARDAN SINGH*, N C SONI and S L SRIVASTAVA ${ }^{\dagger}$ \\ Electroceramics (Ultrasonic Groups), National Physical Laboratory, Dr K S Krishnan Road, New Delhi 110012 , \\ India \\ ${ }^{\dagger}$ Department of Physics and M.N. Saha Centre of Space Studies, University of Allahabad, Allahabad 211 002, India
}

MS received 18 December 2002; revised 15 March 2003

\begin{abstract}
The dielectric and electromechanical properties of lead zirconate titanate $\left[\mathrm{Pb}(\mathrm{Zr}, \mathrm{Ti}) \mathrm{O}_{3}\right]$ ceramic added with neodymium oxide have been systematically studied employing the vector impedance spectroscopic (VIS) technique. The specimens were prepared using the mixed oxide route by adding different mol\% of $\mathrm{Nd}_{2} \mathrm{O}_{3}(0 \cdot 1$ to $7 \mathrm{~mol} \%)$ in $\left[\mathrm{Pb}(\mathrm{Zr}, \mathrm{Ti}) \mathrm{O}_{3}\right]$ near morphotropic phase boundary. Piezoelectric equivalent circuit parameters $R, L, C_{\mathrm{a}}$ in series and $C_{\mathrm{b}}$ in parallel have been determined by simulating $/ Z /$ and $\Theta$ plots. Electromechanical coupling coefficients and strain constants for the radial modes show a peak at about 3 mol\%, the dielectric constant peaks at about $1 \mathrm{~mol} \%$ and voltage constants peak at about $0.75 \mathrm{~mol} \% \mathrm{of} \mathrm{Nd}_{2} \mathrm{O}_{3}$.
\end{abstract}

Keywords. Nd doped lead zirconate titanate; piezoelectric properties; ferroelectric materials; electromechanical parameters; vector impedance measurements.

\section{Introduction}

The lead zirconate titanate $\left[\mathrm{Pb}(\mathrm{Zr}, \mathrm{Ti}) \mathrm{O}_{3}\right]$ ceramics, to which oxides such as $\mathrm{La}_{2} \mathrm{O}_{3}, \mathrm{Nb}_{2} \mathrm{O}_{5}, \mathrm{Fe}_{2} \mathrm{O}_{3}, \mathrm{NiO}, \mathrm{MnO}_{2}$, $\mathrm{IrO}_{2}, \mathrm{ThO}_{2}, \mathrm{WO}_{3}, \mathrm{Cr}_{2} \mathrm{O}_{3}$ and $\mathrm{U}_{3} \mathrm{O}_{8}$ have been added and studied by several workers (Jaffe et al 1971; Thomann 1972; Troccaz et al 1978; Wu et al 1982; Heywang and Thomann 1984; Moulson and Herbert 1990; Katiyar et al $1994,1997)$ due to their wide application in various piezoelectric, ultrasonics and underwater devices along with various actuators and sensors in different fields of science and technology. The effect of addition of rare earth oxides in $\mathrm{Pb}(\mathrm{Zr}, \mathrm{Ti}) \mathrm{O}_{3}$ ceramics have mostly been related with the incorporation of $\mathrm{La}^{+3}$ ions into $\mathrm{Pb}(\mathrm{Zr}, \mathrm{Ti}) \mathrm{O}_{3}$ ceramics which increases their dielectric constant, electromechanical parameters and dielectric loss and decreases mechanical quality factor. The $\mathrm{Pb}(\mathrm{Zr}, \mathrm{Ti}) \mathrm{O}_{3}$ ceramics added with $\mathrm{La}^{+3}$ ions have been extensively studied for both piezoelectric and electro-optical applications but such studies have not been done with other rare earth oxides. It has been reported that the effect of doping of $\mathrm{Sm}^{+3}$ and $\mathrm{Nd}^{+3}$ are similar to $\mathrm{La}^{+3}$ doped lead zirconate titanate ceramics (Wu et al 1982). Some of the dielectric and electromechanical parameters have been reported for few compositions of $\mathrm{Nd}_{2} \mathrm{O}_{3}$ added to $\mathrm{Pb}(\mathrm{Zr}, \mathrm{Ti}) \mathrm{O}_{3}$ near to morphotropic phase boundary (Thomann 1972; Tandon et al 1992), $\mathrm{Pb}_{0.98} \mathrm{Sr}_{0.02}\left(\mathrm{Li}_{0.008} \mathrm{~W}_{0.012} \mathrm{Ti}_{0.46} \mathrm{Zr}_{0.52}\right) \mathrm{O}_{3}(\mathrm{Wu}$ et al 1982) and $\mathrm{Pb}\left(\mathrm{Zr}_{0.95} \mathrm{Ti}_{0.5}\right) \mathrm{O}_{3}$ ceramics (Xue et al

\footnotetext{
*Author for correspondence
}

1990). Inspite of these studies relatively meagre information is available regarding the various dielectric and electromechanical parameters at different levels of $\mathrm{Nd}_{2} \mathrm{O}_{3}$ addition near to morphotropic phase boundary.

It is well known that the electromechanical properties of PZT depend strongly on additives as well as the morphotropic phase boundary. The present investigation was undertaken to study the effect of $\mathrm{Nd}_{2} \mathrm{O}_{3}$ addition to lead zirconate titanate ceramic at 54/46 $\mathrm{Zr} / \mathrm{Ti}$ ratio near the morphotropic phase boundary on the various dielectric and electromechanical parameters. The measurements of various electromechanical parameters were carried out by employing vector impedance spectroscopic (VIS) technique.

\section{Theory}

\subsection{Piezoelectric response}

A single piezoelectric mode is electrically equivalent to $R, L, C_{\mathrm{a}}$ in series and $C_{\mathrm{b}}$ in parallel (see figure 1) and the equivalent impedance, $Z$ of this circuit (Katiyar et al 1994, 1997) is given as

$$
\begin{aligned}
Z & =\frac{\omega_{\mathrm{s}} Q_{\mathrm{m}} R\left[1+j Q_{\mathrm{m}}\left(\omega / \omega_{\mathrm{s}}\right)-\left(\omega_{\mathrm{s}} / \omega\right)\right]}{j \omega r\left[1+j Q_{\mathrm{m}} \sqrt{ }(1+1 / r)\left(\omega / \omega_{\mathrm{p}}\right)-\left(\omega_{\mathrm{p}} / \omega\right)\right]}, \\
& =R_{\mathrm{e}}+j X_{\mathrm{e}},
\end{aligned}
$$

and the admittance $Y=(1 / Z)=G+j B$, where $r$ is capacitive ratio, 


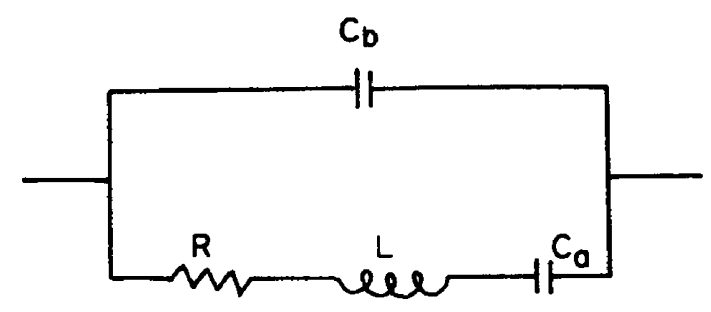

Figure 1. Piezoelectric equivalent circuit.

$$
\omega_{\mathrm{s}}=2 \pi f_{\mathrm{s}}=\left[1 / \sqrt{ }\left(L \cdot C_{\mathrm{a}}\right)\right],
$$

the series resonance angular frequency, is equal to $\left(C_{\mathrm{b}} / C_{\mathrm{a}}\right)$

$$
\omega_{\mathrm{p}}=2 \pi f_{\mathrm{p}}=\omega_{\mathrm{s}} \sqrt{ }[1+(1 / r)],
$$

the parallel resonance angular frequency.

$Q_{\mathrm{m}}=\left(\omega_{\mathrm{s}} \cdot L / R\right)$ is the mechanical quality factor and $M=$ $\left(Q_{\mathrm{m}} / r\right)=1 /\left(\omega_{\mathrm{s}} C_{\mathrm{b}} R\right)$ the figure of merit of this circuit. The frequencies at which the reactance, $X_{\mathrm{e}}$, is zero, are the resonant and anti-resonant frequencies, $f_{\mathrm{r}}$ and $f_{\mathrm{a}}$, respectively and at the frequency, $f_{\mathrm{n}}, Z$ is maximum and at $f_{\mathrm{m}}, Z$ is minimum.

\subsection{Radial modes and piezoelectric parameters}

Radial modes of the thin discs are particularly important in the piezoelectric ceramics, because they are free from the spurious noise and the interference effects. The planar coupling coefficient, $\left(K_{\mathrm{p}}\right)$ of the piezoelectric ceramics may be determined from the measurements of the piezoelectric response on the radial modes. According to IRE standards on piezoelectric crystals (1957 and 1961) the planar coupling coefficient, $K_{\mathrm{p}}$, can be determined with the help of the following equation

$$
\frac{K_{p}^{2}}{1-K_{p}^{2}}=\frac{\begin{array}{c}
{\left[\left(1-\sigma^{\mathrm{E}}\right) J_{1}\left[\Phi\left(1+\Delta f / f_{\mathrm{s}}\right)\right]\right.} \\
\left.-\Phi\left(1+\Delta f / f_{\mathrm{s}}\right) J_{0}\left[\Phi\left(1+\Delta f / f_{\mathrm{s}}\right)\right]\right]
\end{array}}{\left(1-\sigma^{\mathrm{E}}\right) J_{1}\left[\Phi\left(1+\Delta f / f_{\mathrm{s}}\right)\right]},
$$

where $\Delta f=\left(f_{\mathrm{p}}-f_{\mathrm{s}}\right), f_{\mathrm{s}}$ and $f_{\mathrm{p}}$ are series and parallel resonance frequencies.

$J_{0}$ and $J_{1}$ are Bessel functions of first kind and of zero order and first order, respectively and $\sigma^{\mathrm{E}}$ the Poisson's ratio, $\Phi$ the lowest positive root of the following equation

$$
\left(1-\sigma^{\mathrm{E}}\right) J_{1}(\Phi)=\Phi J_{0}(\Phi) \text {. }
$$

It may be noted that $\left(f_{\mathrm{m}}, f_{\mathrm{n}}\right)$ and $\left(f_{\mathrm{r}}, f_{\mathrm{a}}\right)$ are directly measurable, but not $\left(f_{\mathrm{s}}, f_{\mathrm{p}}\right)$. For getting a correct value of $K_{\mathrm{p}}$ using (3), we need $f_{\mathrm{s}}$ and $f_{\mathrm{p}}$ which can be evaluated only when $R, L, C_{\mathrm{a}}$ and $C_{\mathrm{b}}$, are known.

The coupling coefficient, $K_{31}$, may be obtained from $K_{\mathrm{p}}$ and $\sigma^{\mathrm{E}}$ :

$$
K_{31}^{2}=0.5\left(1-\sigma^{\mathrm{E}}\right) K_{\mathrm{p}}^{2} .
$$

The elastic compliance, $s_{11}^{\mathrm{E}}$, may be calculated from

$$
\frac{1}{s_{11}^{\mathrm{E}}}=\frac{4 \pi^{2} a^{2} f_{\mathrm{s}}^{2}\left(1-\sigma E^{2}\right) \rho}{\Phi^{2}},
$$

where ' $a$ ' is the radius of the disc and ' $\rho$ ' the density of the material. The piezoelectric strain constant, $d_{31}$, and the hydrostatic piezoelectric strain constant, $d_{\mathrm{h}}$, may be calculated from the following equations

$$
\begin{aligned}
& d_{31}=K_{31}\left(\varepsilon_{33}^{\mathrm{T}} s_{11}^{\mathrm{E}}\right)^{1 / 2}, \\
& d_{\mathrm{h}}=d_{33}+2 d_{31} .
\end{aligned}
$$

We may note that $d_{31}$ is negative.

The piezoelectric voltage constants, $g_{31}$ and $g_{33}$, may then be calculated from

$$
g_{31}=d_{31} / \varepsilon_{33}^{\mathrm{T}}, g_{33}=d_{33} / \varepsilon_{33}^{\mathrm{T}},
$$

where $\varepsilon_{33}^{\mathrm{T}}$ is the dielectric permittivity of the material.

\section{Experimental}

\subsection{Preparation of specimen}

The LR grade ingredients of $\mathrm{PbO}, \mathrm{ZrO}_{2}, \mathrm{TiO}_{2}$, and $\mathrm{Nd}_{2} \mathrm{O}_{3}$ of the compositions, $\mathrm{Pb}\left(\mathrm{Zr}_{0.54}, \mathrm{Ti}_{0.46}\right) \mathrm{O}_{3}$, were prepared by mixing different molar percentages of $\mathrm{Nd}_{2} \mathrm{O}_{3}(\mathrm{~Pb}(\mathrm{Zr}, \mathrm{Ti})$ $\mathrm{O}_{3}+X \% \mathrm{Nd}_{2} \mathrm{O}_{3}, X=0 \cdot 10$ to $7 \mathrm{~mol} \%$ ) with the help of agate mortar, pestle and acetone as medium. An excess of $1.5 \mathrm{wt} \%$ lead oxide was added in different molar compositions in order to compensate for the lead losses during calcination and subsequent sintering. The mixed materials were initially fired in air at $850^{\circ} \mathrm{C}$ for $2 \mathrm{~h}$. The sample in the form of discs of dimension $16 \mathrm{~mm}$ diameter and $3 \mathrm{~mm}$ thickness was pressed and then sintered at $1250^{\circ} \mathrm{C}$ for $150 \mathrm{~min}$. The sintered discs were lapped and electroded with fired on silver paint. The electroded discs were polarized using a high d.c. electric field of $\sim 3.5 \mathrm{kV} / \mathrm{mm}$ while they were immersed in heated silicon oil at about $130^{\circ} \mathrm{C}$.

\subsection{Measurements}

The electrical measurements were carried out at room temperature using a Hewlett Packard model HP-4194A vector impedance analyser, which was controlled by their computer model HP-300. Impedance /Z/ and phase angle, $\Theta$, of the samples have been measured at different harmonics of the radial modes in the frequency range $0 \cdot 15-$ $1.5 \mathrm{MHz}$. The charge constant, $d_{33}$, was measured by using a Berlincourt's $d_{33}$ meter model CPDT-3300 (Channel Products Inc. USA).

\section{Results and discussion}

The piezoelectric equivalent circuit parameters, $R, L, C_{\mathrm{a}}$ and $C_{\mathrm{b}}$, were obtained from the simulated fitting of $|Z|$ 
Table 1. Measured and derived values of dielectric, $K_{3}^{\mathrm{T}}$, tan $\delta$, elastic and electromechanical parameters, $s_{11}^{\mathrm{E}}, d_{33}, d_{31}, d_{\mathrm{h}}, g_{33}$ and $g_{31}$ at different $\mathrm{mol} \%$ of $\mathrm{Nd}_{2} \mathrm{O}_{3}$ additions in $\mathrm{Pb}\left(\mathrm{Zr}_{0.54}, \mathrm{Ti}_{0.46}\right) \mathrm{O}_{3}$.

\begin{tabular}{|c|c|c|c|c|c|c|c|c|c|c|}
\hline \multirow[b]{2}{*}{ Sl. no. } & \multirow{2}{*}{$\begin{array}{l}\mathrm{Nd}_{2} \mathrm{O}_{3} \\
(\mathrm{~mol} \%)\end{array}$} & \multirow[b]{2}{*}{$K_{3}^{\mathrm{T}}$} & \multirow[b]{2}{*}{$\tan \delta$} & \multirow[b]{2}{*}{$K_{\mathrm{p}}$} & \multirow{2}{*}{$\begin{array}{c}s^{\mathrm{E}}{ }_{11} \\
\left(\times 10^{-12} \mathrm{~m}^{2} / \mathrm{N}\right)\end{array}$} & $d_{33}$ & $d_{31}$ & $d_{h}$ & $g_{33}$ & $g_{31}$ \\
\hline & & & & & & \multicolumn{3}{|c|}{$\left(\times 10^{-12} \mathrm{C} / \mathrm{N}\right)$} & \multicolumn{2}{|c|}{$(\mathrm{mV} \cdot \mathrm{m} / \mathrm{N})$} \\
\hline 1. & $0 \cdot 10$ & 424 & $0 \cdot 006$ & $0 \cdot 27$ & 15 & 135 & 38 & 59 & 36 & 10 \\
\hline 2. & $0 \cdot 50$ & 818 & $0 \cdot 016$ & $0 \cdot 51$ & 17 & 370 & 104 & 162 & 51 & 14 \\
\hline 3. & 0.75 & 748 & $0 \cdot 019$ & 0.52 & 19 & 380 & 107 & 166 & 57 & 16 \\
\hline 4. & 1.00 & 1296 & 0.027 & 0.56 & 20 & 405 & 153 & 99 & 35 & 13 \\
\hline 5. & $3 \cdot 00$ & 1218 & 0.015 & 0.59 & 20 & 422 & 157 & 108 & 39 & 15 \\
\hline 6. & $5 \cdot 00$ & 1026 & $0 \cdot 017$ & $0 \cdot 39$ & 12 & 257 & 74 & 109 & 28 & 8 \\
\hline 7. & $7 \cdot 00$ & 850 & $0 \cdot 017$ & $0 \cdot 34$ & 12 & 214 & 58 & 98 & 28 & 8 \\
\hline
\end{tabular}

and $\Theta$ with experimental curves. For the fundamental mode measured values of dielectric constant, $K_{3}^{\mathrm{T}}$, loss factor, $\tan \delta$, and piezoelectric parameters, $s_{11}^{\mathrm{E}}, d_{33}, d_{31}$, $d_{\mathrm{h}}, g_{33}$ and $g_{31}$ (taking the value of $\sigma^{\mathrm{E}}=0.34$ from Katiyar et al 1994, 1997) at different mol\% of $\mathrm{Nd}_{2} \mathrm{O}_{3}$ additions in $\mathrm{Pb}\left(\mathrm{Zr}_{0.54}, \mathrm{Ti}_{0.46}\right) \mathrm{O}_{3}$ are listed in table 1 .

The addition of neodymium causes significant changes on electromechanical properties which may be seen in table 1 . The correct values of $K_{\mathrm{p}}$ determined for different labels of $\mathrm{Nd}^{+3}$ doping using (3) are also reported (table $1)$. The piezoelectric parameter, $K_{\mathrm{p}}$, charge constant, $d_{33}$ and $d_{31}$, show a peak at $3 \mathrm{~mol} \%, K_{3}^{\mathrm{T}}$ peaks at $1 \mathrm{~mol} \%$ whereas $d_{\mathrm{h}}, g_{33}$ and $g_{31}$ peaks around $0.75 \mathrm{~mol} \%$ of $\mathrm{Nd}_{2} \mathrm{O}_{3}$. Thomann (1972) reported $K_{3}^{\mathrm{T}}$, and coercive field of one composition of $\mathrm{Pb}\left(\mathrm{Zr}_{0.53}, \quad \mathrm{Ti}_{0.47}\right) \mathrm{O}_{3}+1 \mathrm{wt} \%$ $\mathrm{Nd}_{2} \mathrm{O}_{3}$ and Tandon et al (1992) found that dielectric constant, $K_{3}^{\mathrm{T}}$, loss tangent, $(\tan \delta)$ increase with addition of $\mathrm{Nd}_{2} \mathrm{O}_{3}$ and $d_{33}$ and $g_{33}$ peaks at $2 \mathrm{~mol} \%$ of $\mathrm{Nd}_{2} \mathrm{O}_{3}$ and peak value of $d_{33}$ reported by them is lower than the values reported here. Maximum values of the elastic, piezoelectric and dielectric parameters i.e. $s_{11}^{\mathrm{E}}, d_{31}, g_{31}$, $K_{31}$ and dielectric constant, $K_{3}^{\mathrm{T}}$, of Nd doped lead zirconate titanate (PZT) reported here are larger than those of Cr doped PZT (Katiyar et al 1994) and Mn doped PZT (Katiyar et al 1997).

\section{Conclusion}

With these observed enhanced electromechanical parameters, it may be remarked that the effect of $\mathrm{Nd}_{2} \mathrm{O}_{3}$ doping is similar to $\mathrm{La}_{2} \mathrm{O}_{3}$ doped lead zirconate titanate ceramic materials. Since lead zirconate titanate ceramics added with neodymium ions have enhanced dielectric and electromechanical properties, they may therefore find special applications in piezoelectric, ultrasonic and underwater acoustic transducer devices.

\section{Acknowledgements}

The author thanks Dr Krishan Lal, Director, National Physical Laboratory, New Delhi for his constant interest and encouragement. One of us (SLS) thanks ISRO, Bangalore, for the grant of a research project entitled "Study of Microwave Ceramics".

\section{References}

Heywang W and Thomann H 1984 Ann. Rev. Mater. Sci. 1427 IRE Standards on Piezoelectric Crystals 1957 Proc. IRE 45354 IRE Standards on Piezoelectric Crystals 1961 Proc. IRE 49 1161

Jaffe B, Cook W R and Jaffe H 1971 Piezoelectric ceramics (London: Academic Press)

Katiyar V K, Srivastava S L and Singh Janardan 1994 J. Appl. Phys. 761131

Katiyar V K, Srivastava S L and Singh Janardan 1997 Ferroelectrics 19321

Moulson A J and Herbert J M 1990 Electroceramics (London: Chapman and Hall)

Tandon R P, Singh V and Swami N N 1992 J. Mater. Sci. Lett. 11327

Thomann H 1972 Ferroelectrics 4141

Troccaz M, Gonnard P and Eyraud L 1978 Ferroelectrics 2217

Wu Long, Lee Chung-Chang, Wu Tien Shou and Wei ChungChuang 1982 Ferroelectrics 41157

Xue W R, Schulze W A and Newnham R E 1990 J. Am. Ceram. Soc. 731783 